\title{
The Effect of Microwave Treatment on Ryegrass and Wild Radish Plants and Seeds
}

\author{
Graham Brodie* and Eloise Hollins
}

\author{
Melbourne School of Land and Environment, Melbourne University, Dookie Campus, Nalinga Rd., Dookie \\ 3647, Australia
}

\begin{abstract}
Annual ryegrass (Lolium rigidum) and wild radish (Raphanus raphanistrum) are significant weeds in Australian winter cropping systems. These species have developed significant herbicide resistance and new control strategies need to be developed. Microwave energy has been considered for weed control for some time. The research considered the effect of varying amounts of microwave energy on plants and their seeds for each species. Several experiments explored the interaction between microwave energy and seed depth in the soil. Plant responses to microwave energy were also determined for each species. Seed treatment requires higher energy applications than plant treatment and is conceptually similar to soil fumigation treatments. Soil treatment may have application in some high value horticultural crops, which already use soil fumigation. Microwave treatment of plants requires less energy, with wild radish requiring about $60 \mathrm{~J} \mathrm{~cm}^{-2}$ to achieve $100 \%$ mortality, while ryegrass plants require about $370 \mathrm{~J} \mathrm{~cm}^{-2}$ to achieve $100 \%$ mortality. Microwave treatment of growing plants can be compared to the application of herbicide. Therefore control of growing plants should be the focus of developing a commercially viable microwave weed control device for cropping systems.
\end{abstract}

Keywords: Microwave, weed, ryegrass, wild radish.

\section{INTRODUCTION}

Annual ryegrass (Lolium rigidum) and wild radish (Raphanus raphanistrum) are considered to be the most serious and challenging weeds of annual winter cropping systems in southern Australia [1, 2]. They have developed resistances to herbicides from several groups [3] and pose a significant threat to the future of Australian agriculture, in regards to production loss [4] and financial burdens. Interest in chemical-free weed control has been increasing due to concerns over herbicide resistance, the environmental and human health impacts of herbicide use [5, 6], and the rise in organic farming practices.

Microwave radiation has long been considered as a suitable technology to control the weed seed bank [7-9]; however, it failed to reach commercial use. This was due to numerous studies agreeing that it was far too inefficient and impractical for broad acre seed bank control [10-13]. In spite of this, the growing concern of herbicide resistance has prompted a revisit of microwave weed control technology, with a focus on overcoming these inefficiencies. Achieving these goals requires a better understanding of the microwave energy requirements for treating weeds and their seeds in the soil.

*Address correspondence to this author at the Melbourne School of Land and Environment, Melbourne University, Dookie Campus, Nalinga Rd., Dookie 3647, Australia; Tel: +61 3 58339273; Fax: +61 3 58339201;

E-mail: grahamb@unimelb.edu.au

\section{METHOD}

This research used a series of small well defined experiments to determine the dose response curves for annual ryegrass and wild radish weeds and their seeds to varying amounts of microwave energy. In the particular case of seeds, soil depth will also affect the susceptibility of seeds to microwave treatment; therefore soil depth must be accounted for in the dose response curves for seed treatments. All experiments were run using a horn antenna to apply the microwave energy to the plants or soil. Each experimental treatment had at least four replicates and each experiment was performed at least twice to verify the results.

\subsection{Estimating Microwave Power Density from a Horn Antenna}

The prototype systems use in this study used a rectangular wave guide feeding microwaves into a pyramidal horn antenna, which projects the microwave energy vertically onto the ground. The microwave energy generates heat within the plants and soil.

Microwave heating is directly linked to the dielectric properties of the plants and soil and the electrical field strength of the microwave fields [14]; therefore it is critical to understand the field intensity and distribution on the surface of the soil. It is unsafe to directly measure the field intensity near the microwave applicator; therefore was necessary to estimate the field energy density, based on well-established electromagnetic theory. 
The electric field in the wave guide has a sinusoidal distribution across the width of the guide. The peak electric field strength $\left(E_{o}\right)$ in a rectangular wave guide is [15]:

$$
E_{o}=\sqrt{\frac{8 \pi \mathrm{f} \mu_{\mathrm{o}} P}{a b \sqrt{\left(\frac{2 \pi f}{c}\right)^{2}-\left(\frac{\pi}{a}\right)^{2}}}}
$$

Where $\mu_{o}$ is the permeability of free space, $P$ is the average microwave power $(\mathrm{W})$, $a$ is the width of the wave guide $(m), b$ is the height of the wave guide $(m)$, and $\mathrm{c}$ is the speed of light in free space $\left(\mathrm{m} \mathrm{s}^{-1}\right)$.

The distribution of the microwave's electric field across the width of the waveguide, as measured from the centre line of the guide, is:

$$
E=E_{o} \cos \left(\frac{\pi}{a} x^{\prime}\right)
$$

Where $x^{\prime}$ is the horizontal distance in the aperture plane from the centre line of the wave guide or aperture $(m)$. There is some expansion of the field between the feeding wave guide and the aperture of the antenna; therefore:

$$
E_{a}=E_{o} \cos \left(\frac{\pi}{A} x^{\prime}\right) \cdot \frac{a}{A}
$$

Where $A$ is the width of the aperture $(m)$.

In order to properly understand the field intensity at the soil surface, and therefore determine the microwave energy that has been applied to the soil, an analysis of the microwave field intensity immediately in front of a pyramidal horn antenna (in the Near Field) is required. This problem is not trivial.

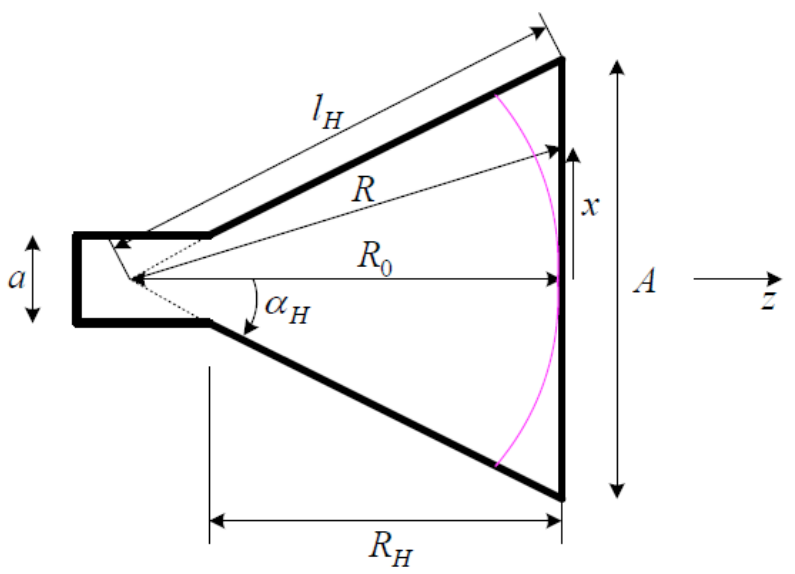

Figure 1: Geometry of a horn antenna showing a propagating wave front in the flare of the antenna [16].
Based on the geometry of the horn antenna sown in Figure 1, the problem can be described by:

$E_{P}=$

$\frac{E_{a}}{4 \pi} \int_{-B / 2-A / 2}^{B / 2} \int_{-A / 2}^{A} \cos \left(\frac{\pi}{A} x^{\prime}\right) \frac{e^{-j \beta_{o}\left(\sqrt{\left(x-x^{\prime}\right)^{2}+\left(y-y^{\prime}\right)^{2}+z^{2}}+\sqrt{R_{o}{ }^{2}+\left(x^{\prime}\right)^{2}}+\sqrt{R_{o}^{2}+\left(y^{\prime}\right)^{2}}\right)}}{\sqrt{\left(x-x^{\prime}\right)^{2}+\left(y-y^{\prime}\right)^{2}+z^{2}}} \cdot d x^{\prime} \cdot d y^{\prime}$

Where $x, y$, and $z$ is the Cartesian coordinates of the point relative to the centre point of the antenna's aperture and $x^{\prime}$ and $y^{\prime}$ are the Cartesian coordinates of any point in the antenna's aperture plane relative to the centre point of the antenna's aperture.

There is no simple closed solution to Equation (4); however it can be evaluated numerically using a Simpson's numerical surface integral approximation. This numerical integration was coded using MatLab ${ }^{\circledR}$ and used to estimate the field energy intensity on a plane at ground level for various heights of the horn antenna above the ground plane. This is essential to properly determine the dose responses of weeds and their seeds to applied microwave energy. Figure 2 shows the estimated field strength as a function of range from the horn antenna to the ground plane and lateral distance from the centre line of the horn antenna.

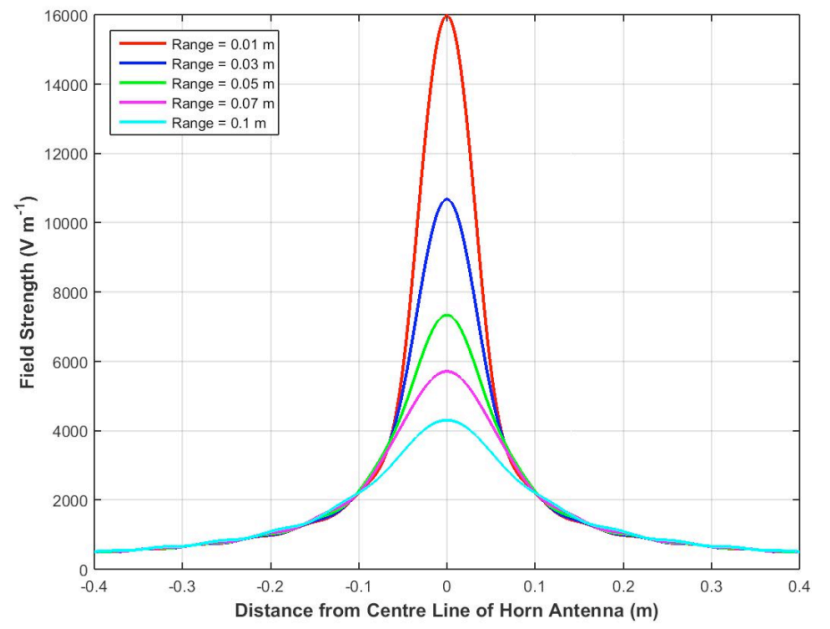

Figure 2: Estimated microwave field strength at ground level from a $2 \mathrm{~kW}$ microwave system as a function of height of the $110 \mathrm{~mm}$ by $55 \mathrm{~mm}$ antenna above the ground.

\subsection{Experiment 1 - Ryegrass Seed Treatment in Sand}

The laboratory microwave system (Figure 3), based on a modified $750 \mathrm{~W}$ microwave oven operating at 2.45 $\mathrm{GHz}$, had an $86 \times 43 \mathrm{~mm}$ rectangular waveguide channelling the microwaves from the oven's magnetron to a pyramidal horn antenna with aperture dimensions of $180 \times 90 \mathrm{~mm}$. 


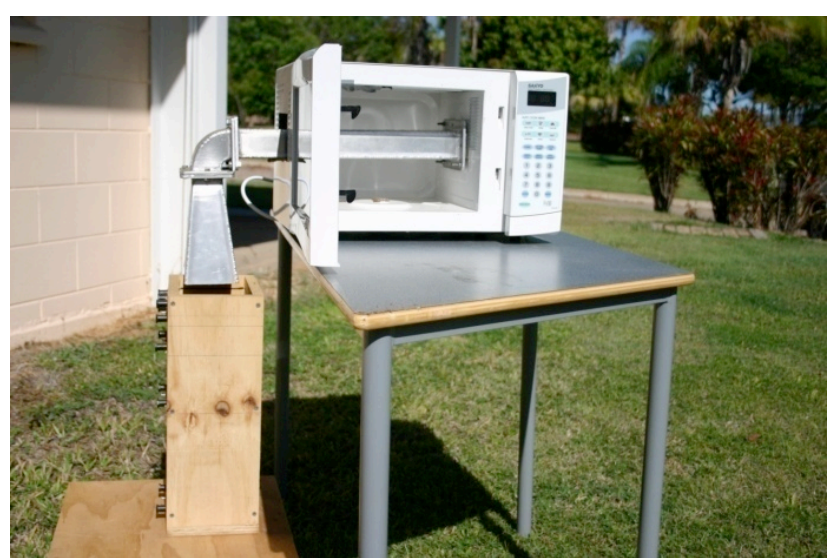

Figure 3: Microwave prototype system based on a modified microwave oven.

Fine builder's sand was used for this experiment. Dry sand has the lowest dielectric constant at microwave frequencies of any air-dry soil type $[17,18]$. Therefore, sand was chosen to represent the "worst case scenario" for microwave treatment of soil seed banks. The sand was sieved through a $1 \mathrm{~mm}$ soil sieve to ensure homogeneity of soil behaviour during the experiments. The sand was air-dried during summer and then stored in a warm dry environment until used in the experiments. Gravimetric analysis, based on weights before and after drying for $24 \mathrm{~h}$ at $105^{\circ} \mathrm{C}$, was used to determine that the moisture content of the airdry sand was $1.0 \%$.

A $2 \times 5 \times 4$ factorial experiment was conducted. Factor A involved soils at two moisture levels: air dry and $20 \%$ water by volume. The wet soil was prepared by mixing four parts by volume of sand with one part by volume of water and then mixing thoroughly by hand. Factor B comprised five microwave heating times: 0,2 , 4,8 , and $12 \mathrm{~min}$. Factor $\mathrm{C}$ involved burying the ryegrass seeds at four different depths $(0,2,5$, or 10 $\mathrm{cm}$ ) from the surface of the soil that was exposed to the microwave energy.

Samples of twenty seeds were placed into paper envelopes made from folded filter paper to facilitate easy recovery from the soil after treatment. Fifty two pots were used in the experimental protocol, with four seed envelopes placed in the centre of each pot at the appropriate depth from the surface. The pots were allowed to stand for at least $15 \mathrm{~min}$ before any experimental procedures were imposed. This allowed the seeds and seed envelopes to reach thermal and moisture equilibrium with the sand. Pots were placed under the horn antenna of the microwave prototype at a range of $20 \mathrm{~mm}$ from the antenna's aperture and exposed to microwave treatment for the appropriate amount of time.
After the sand had cooled, the seeds were extracted and placed on top of moist cotton wool and filter paper in petri dishes. The petri dishes were covered and incubated in a Contherm incubator (model CAT 150) at $28^{\circ} \mathrm{C}$, which was within the temperature range for optimal ryegrass seed germination [19]. The seeds were kept moist and checked regularly to ensure they did not dry out. The seeds were allowed to germinate for ten days. Seeds were regarded as having germinated if the radical had emerged.

\subsection{Experiment 2 - Ryegrass Seed Treatment in Soil}

Thirty five soil samples were randomly excavated from the top $3 \mathrm{~cm}$ of a paddock at the Dookie campus of the University of Melbourne that was predominantly "Currawa Loam". The soil was layered into pots with sets of 25 ryegrass seeds in paper envelopes placed at depths of $0,2,5,10$ and $20 \mathrm{~cm}$ within each pot. The pots received $500 \mathrm{ml}$ of water to reach a consistent moisture level and left overnight.

This microwave treatment was applied using a $2 \mathrm{~kW}$ microwave system operating at $2.54 \mathrm{GHz}$ feeding into a horn antenna with aperture dimensions of $110 \mathrm{~mm}$ by $55 \mathrm{~mm}$. Each pot was placed under the microwave antenna at a range of $70 \mathrm{~mm}$ from the antenna's aperture for treatment durations of $0,2,5,10,30$ and 120 seconds. Pots were left to return to ambient temperature. After cooling, each layer of seeds was carefully removed and placed into individual bags labelled with the pot number, treatment and soil depth. In order to promote germination, seeds were placed between layers moistened paper towel, within a small, open plastic bag and kept in a warm, dark place. The paper towel was remoistened each day. After 10 days, the total number of germinated seeds was recorded to determine the percentage of germination following microwave treatment.

\subsection{Experiment 3 - Ryegrass Plants in Soil}

Ninety soil samples from the top $3 \mathrm{~cm}$ of the same paddock as used in Experiment 2 were excavated and placed into pots. Each pot was allocated 20 annual ryegrass seeds, which were grown for nine weeks. The seeds were randomly placed on the soil surface and topped with a shallow covering of soil. Initially, the seeds were watered in with $500 \mathrm{ml}$ of water per pot. Over the growing period, pots were watered with $100 \mathrm{ml}$ of water every 3 days to ensure the soil remained moist. After one week most seeds had germinated and 
after a month many plants were well established. The total number of established seeds was recorded.

Three degrees of water stress were established to test the relationship between water stress and microwave treatment on ryegrass plants. One group of plants received a regular watering schedule of $100 \mathrm{ml}$ every 3 days up until the day of microwave treatment. This group was named 'Water Stress Group A'. The second degree of water stress was established by the cessation of watering of a number of pots 5 days prior to microwave treatment. This group was named 'Water Stress Group B'. A third degree of water stress was achieved by pots in this group receiving no water from 10 days prior to microwave treatment. This group was named 'Water Stress Group C'. The difference this water restriction treatment caused was determined by the gravimetric water contents of the soils from each water stress group. Ten randomly selected soil samples were taken from each group and weighed. The samples were oven dried at $105^{\circ} \mathrm{C}$ for 24 hours and then a dry weight was recorded to calculate the average gravimetric water content of each group.

Once plants were well established, each pot was placed under the antenna of the $2 \mathrm{~kW}, 2.45 \mathrm{GHz}$, microwave system with a $110 \mathrm{~mm}$ by $55 \mathrm{~mm}$ antenna aperture at a range of $110 \mathrm{~mm}$, for treatment durations of $0,2,5,10,30$ and 120 seconds. One day after treatment, all pots received $100 \mathrm{ml}$ of water every 3 days for a total of 10 days to encourage recovery and growth of the ryegrass plants. After this time, the number of living and dead plants in each pot was recorded to determine the percentage of plant survival following microwave treatment.

\subsection{Experiment 4 - Wild Radish Seeds in Soil}

Twenty soil samples were randomly excavated from the top $3 \mathrm{~cm}$ of a paddock at the Dookie campus of the University of Melbourne that was predominantly "Currawa Loam". The soil was layered into pots with sets of 20 wild radish seeds, which were removed from their pods and placed into paper envelopes, at depths of $0.5,5.0$ and $9.5 \mathrm{~cm}$ within each pot. The pots received $500 \mathrm{ml}$ of water to reach a consistent moisture level and left overnight. On the following day the pots were exposed to microwave treatment.

This experiment was conducted using a $2.54 \mathrm{GHz}$, $2 \mathrm{~kW}$ microwave system, feeding into a horn antenna with aperture dimensions of $110 \mathrm{~mm}$ by $55 \mathrm{~mm}$. Each pot was placed under the microwave antenna at a range of $55 \mathrm{~mm}$ from the antenna's aperture for treatment durations of $0,15,30,60$, and 90 seconds. Pots were left to return to ambient temperature. Each layer of seeds was carefully removed and placed onto moist filter paper in petri dishes. After 10 days, the total number of germinated seeds was recorded to determine the percentage of germination following microwave treatment.

\subsection{Experiment 5 - Wild Radish Plants in Soil}

Sixty soil samples from the top $3 \mathrm{~cm}$ of the same paddock used in Experiment 2 were excavated and placed into pots. Each pot was allocated 3 to 4 wild radish seeds, which were grown for six weeks. Initially, the seeds were watered in with $500 \mathrm{ml}$ of water per pot. Over the growing period, pots were watered with 100 $\mathrm{ml}$ of water every 3 days to ensure the soil remained moist. Not all seeds germinated, so after three weeks, pots with more than one plant were thinned to one plant per pot.

Once plants had developed to a rosette stage, each pot was placed under the antenna of the $2 \mathrm{~kW}, 2.45$ $\mathrm{GHz}$, microwave system at a range of $110 \mathrm{~mm}$, for treatment durations of $0,5,10,15,30$ and 60 seconds. One day after treatment, pots received $100 \mathrm{ml}$ of water every 3 days for a total of 10 days to encourage growth of the plants. After this time, the number of plants still alive was recorded to determine the percentage plant survival following microwave treatment.

\subsection{Statistical Analyses}

Analysis of variance was used to determine significant differences in plant and seed survival. Weed control studies require the determination of dose response curves, relating applied microwave energy (and soil depth in the case of seeds). These were determined by regression using MatLab ${ }^{\circledR}$.

\section{RESULTS}

\subsection{Experiment 1 - Ryegrass Seed Treatment in} Sand

Seed mortality increasing as applied microwave energy increased; however increasing burial depth reduced seed mortality (Table 1 ). Significantly less microwave energy was needed to achieve high seed mortality in wet sand than in dry sand (Table 1).

Seed response as a function of microwave energy and seed burial depth can be described by dose 
Table 1: Mean Ryegrass Seed Germination Percentage as a Function of Applied Microwave Energy and Seed Depth

\begin{tabular}{|c|c|c|c|c|c|c|c|c|c|c|c|c|}
\hline \multirow{2}{*}{ Burial Depth (cm) } & \multicolumn{6}{|c|}{ Dry Sand Microwave Energy $\mathrm{J} \mathrm{cm}^{-2}$} & \multicolumn{6}{|c|}{ Wet Sand Microwave Energy $\mathrm{J} \mathrm{cm}^{-2}$} \\
\hline & 0 & 588 & 1176 & 2352 & 2940 & 3528 & 0 & 588 & 1176 & 2352 & 2940 & 3528 \\
\hline 0 & $59.4^{\mathrm{ab}}$ & $58.5^{\mathrm{ab}}$ & $59.8^{\mathrm{ab}}$ & $59.9^{\mathrm{ab}}$ & $25.6^{b}$ & $1.3^{\mathrm{c}}$ & $56.7^{\mathrm{ab}}$ & $57.1^{\mathrm{ab}}$ & $0.0^{c}$ & $1.3^{\mathrm{c}}$ & $0.0^{c}$ & $3.8^{c}$ \\
\hline 2 & $75.0^{\mathrm{a}}$ & $54.7^{\mathrm{ab}}$ & $71.9^{\mathrm{a}}$ & $46.4^{b}$ & $28.1^{b}$ & $2.5^{c}$ & $62.6^{\mathrm{ab}}$ & $62.1^{\mathrm{ab}}$ & $0.0^{c}$ & $0.0^{c}$ & $0.0^{\mathrm{c}}$ & $0.0^{\mathrm{c}}$ \\
\hline 5 & $62.9^{\mathrm{ab}}$ & $65.4^{\mathrm{ab}}$ & $57.6^{\mathrm{ab}}$ & $62.6^{\mathrm{ab}}$ & $57.6^{\mathrm{ab}}$ & $47.2^{b}$ & $64.7^{\mathrm{ab}}$ & $42.0^{\mathrm{b}}$ & $0.0^{c}$ & $0.0^{c}$ & $0.0^{c}$ & $4.9^{c}$ \\
\hline 10 & $72.0^{\mathrm{a}}$ & $47.0^{\mathrm{ab}}$ & $70.4^{\mathrm{ab}}$ & $54.7^{\mathrm{ab}}$ & $68.7^{\mathrm{ab}}$ & $62.0^{\mathrm{ab}}$ & $59.3^{\mathrm{ab}}$ & $67.0^{\mathrm{ab}}$ & $58.0^{\mathrm{ab}}$ & $0.0^{c}$ & $0.8^{\mathrm{c}}$ & $0.0^{c}$ \\
\hline \multicolumn{12}{|c|}{$\operatorname{LSD}(P=0.05)$} & 25.3 \\
\hline
\end{tabular}

Note: Entries with different superscripts are significantly different from one another.

response surfaces. The Normalised dose response for seeds in dry sand is described by Figure 4.

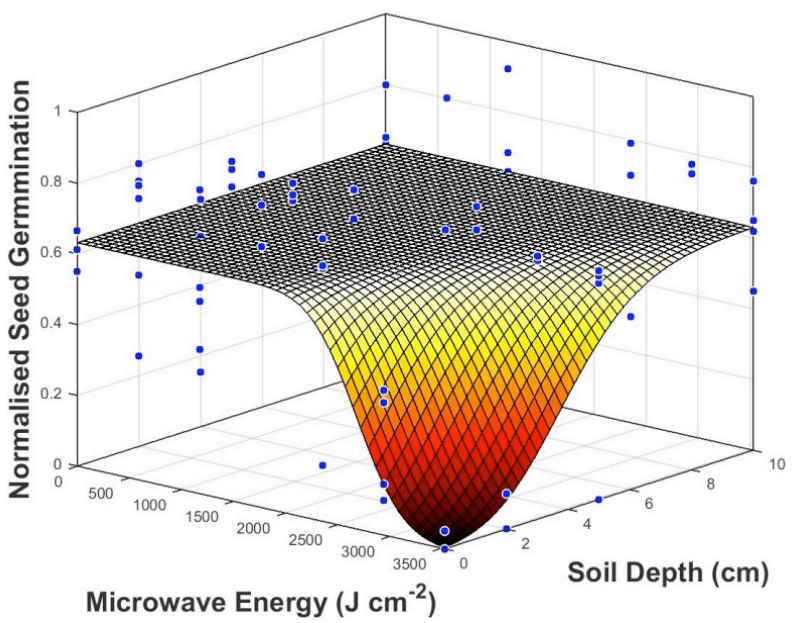

Figure 4: Normalised germination response for annual ryegrass seeds in dry sand as a function of applied microwave energy and seed depth.

$S=0.41 \cdot \operatorname{erfc}\left[0.002\left(E \cdot e^{-0.07 D}-2682\right)\right]$

Where $\mathrm{E}$ is the applied microwave energy $\left(\mathrm{J} \mathrm{cm}^{-2}\right)$ and $D$ is the depth $(m)$. The $r^{2}$ value for this function is 0.93 .

Note: $\operatorname{erfc}(z)=\frac{1}{\sqrt{2 \pi}} \int_{z}^{\infty} e^{\frac{t^{2}}{2}} \cdot d t-$ is the complementary Gaussian error function and assumes that the susceptibility of plants and seeds to microwave treatment is normally distributed. Including a term with the form $E \cdot e^{-\alpha D}$ will account for the natural attenuation of the microwave energy with depth in the soil.

Microwave heating in wet sand was much faster and therefore required far less energy to kill the ryegrass seeds (Figure 5). The Normalised dose response is described by:

$$
S=0.30 \cdot \operatorname{erfc}\left[0.022\left(E \cdot e^{-0.07 D}-646\right)\right]
$$

The $r^{2}$ value for this function is 0.97 .

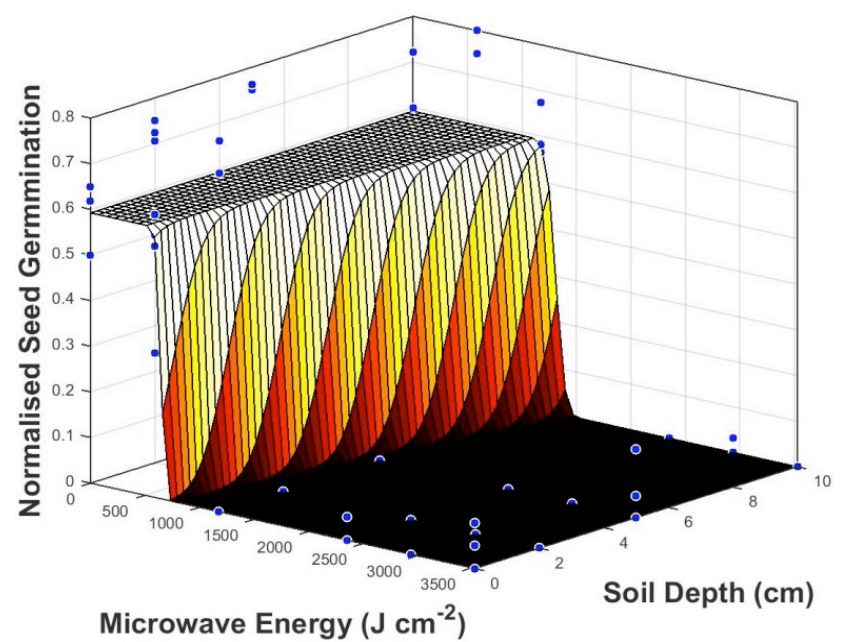

Figure 5: Normalised germination response for annual ryegrass seeds in wet sand as a function of applied microwave energy and seed depth.

\subsection{Experiment 2 - Ryegrass Seed Treatment in Soil}

As in the previous experiment, ryegrass seed mortality increased with increasing microwave energy, but decreased with increasing burial depth (Table 2). The Normalised dose response (Figure 6 ) is described by:

$$
S=0.42 \cdot \operatorname{erfc}\left[0.01\left(E \cdot e^{-0.045 D}-561.3\right)\right]
$$

The $r^{2}$ value for this function is 0.85 .

\subsection{Experiment 3 - Ryegrass Plants in Soil}

Microwave induced soil temperature was higher in the water stressed treatments than in the unstressed treatments (Figure 7); especially in the highest microwave treatment. The mean level of soil moisture for each water stress groups varied from $5 \%$ to $14 \%$ (Figure 8), according to the applied treatments; however there were no statistically significant differences in plant responses that could be attributed 
Table 2: Mean Ryegrass Seed Germination Percentage as a Function of Applied Microwave Energy and Seed Depth

\begin{tabular}{|c|c|c|c|c|c|c|c|}
\hline \multirow{2}{*}{$\begin{array}{c}\text { Burial } \\
\text { Depth }(\mathrm{cm})\end{array}$} & \multicolumn{7}{|c|}{ Applied Microwave Energy $\left(\mathrm{J} \mathrm{cm}^{-2}\right)$} \\
\hline & 0 & 17 & 42.5 & 85 & 255 & 510 & 1020 \\
\hline 0.00 & $84.6^{\mathrm{a}}$ & $87.4^{\mathrm{a}}$ & $82.8^{\mathrm{ab}}$ & $85.0^{\mathrm{a}}$ & $69.9^{b}$ & $67.2^{\mathrm{b}}$ & $7.4^{\mathrm{c}}$ \\
\hline 2.00 & $74.6^{b}$ & $88.2^{\mathrm{a}}$ & $91.1^{\mathrm{a}}$ & $84.1^{\mathrm{ab}}$ & $81.9^{\mathrm{ab}}$ & $70.3^{b}$ & $1.6^{\mathrm{c}}$ \\
\hline 5.00 & $83.8^{\mathrm{ab}}$ & $85.9^{\mathrm{a}}$ & $85.7^{\mathrm{a}}$ & $89.0^{\mathrm{a}}$ & $89.1^{\mathrm{a}}$ & $89.0^{\mathrm{a}}$ & $6.6^{\mathrm{c}}$ \\
\hline 10.00 & $71.4^{\mathrm{b}}$ & $86.1^{\mathrm{a}}$ & $91.7^{\mathrm{a}}$ & $86.6^{\mathrm{a}}$ & $86.7^{\mathrm{a}}$ & $86.7^{\mathrm{a}}$ & $86.2^{\mathrm{a}}$ \\
\hline 15.00 & $77.8^{\mathrm{ab}}$ & $85.8^{\mathrm{a}}$ & $89.0^{\mathrm{a}}$ & $85.3^{\mathrm{a}}$ & $84.3^{\mathrm{a}}$ & $84.8^{\mathrm{a}}$ & $85.2^{\mathrm{a}}$ \\
\hline 20.00 & $84.1^{\mathrm{a}}$ & $85.5^{\mathrm{a}}$ & $86.2^{\mathrm{a}}$ & $84.1^{\mathrm{a}}$ & $81.8^{\mathrm{a}}$ & $83.0^{a}$ & $84.3^{\mathrm{a}}$ \\
\hline \multicolumn{7}{|c|}{$\operatorname{LSD}(P=0.05)$} & 9.9 \\
\hline
\end{tabular}

Note: Entries with different superscripts are significantly different from one another.

to these moisture stresses. Therefore the dose response was determined on the pooled response of all pots in the experiment (Figure 9).

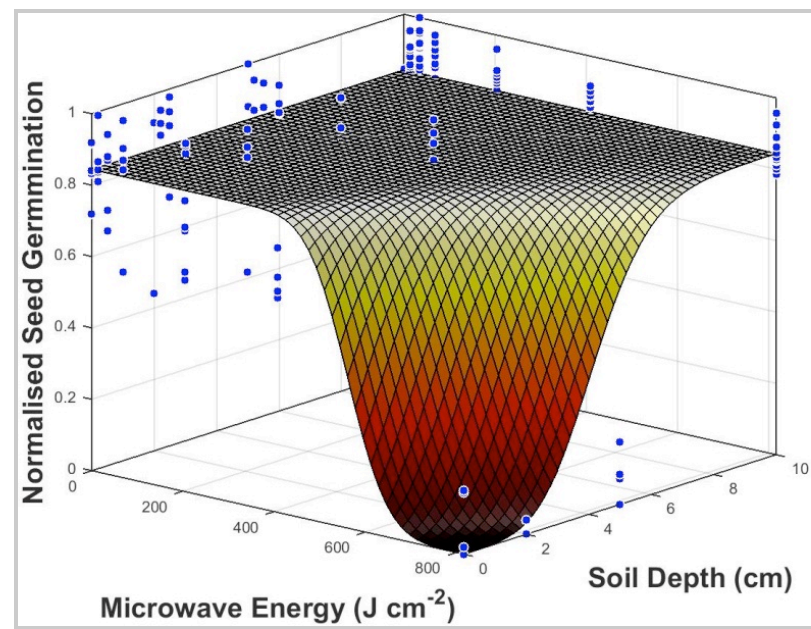

Figure 6: Normalised germination response for annual ryegrass seeds in soil as a function of applied microwave energy and seed depth.

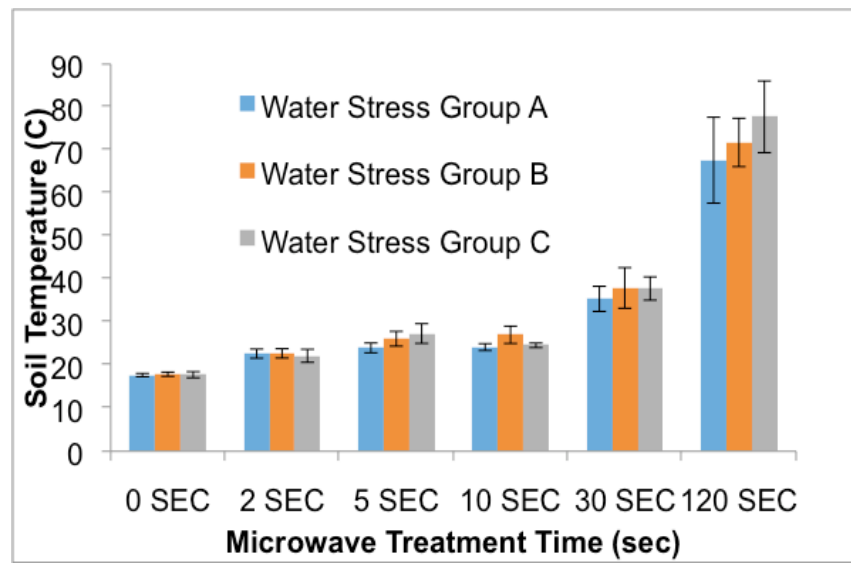

Figure 7: Soil temperature in relation to microwave treatment time, across three water stress groups A, B and C. Standard deviations shown as error bars.

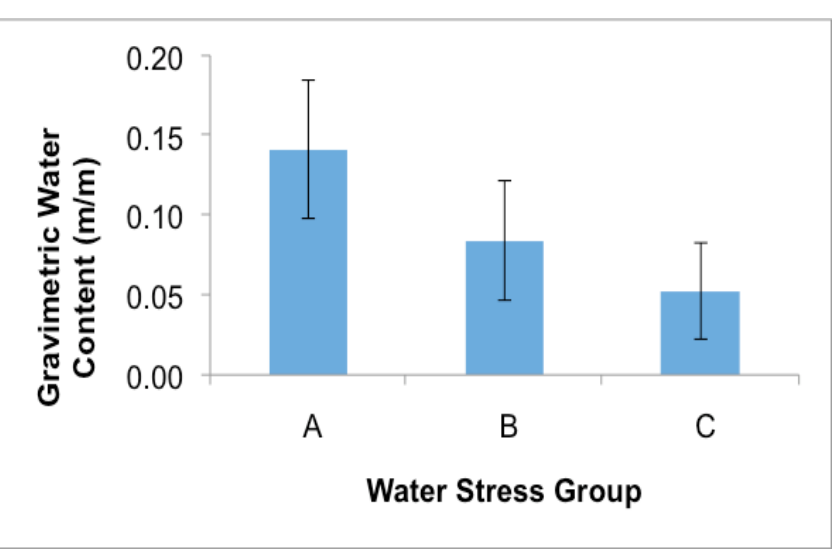

Figure 8: Gravimetric water content of soil following imposition of three water stress groups, A, B and C.

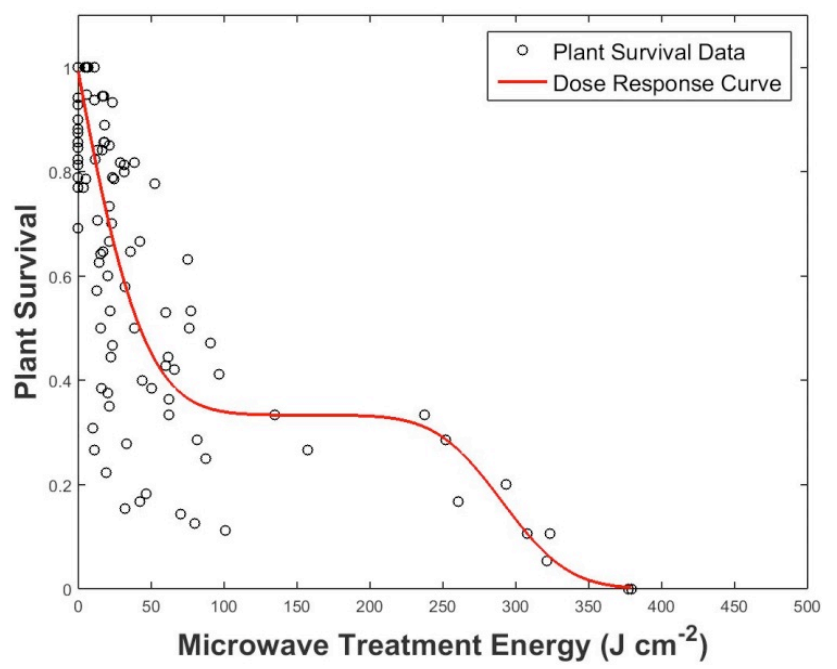

Figure 9: Response of annual ryegrass plants as a function of applied microwave energy.

The Normalised dose response is described by:

$$
\begin{aligned}
& S=0.17 \cdot \operatorname{erfc}[0.02(E-290.7)] \\
& +0.83 \cdot \operatorname{erfc}[0.017(E+11.05)]
\end{aligned}
$$


Table 3: Mean Wild Radish Seed Germination Percentage as a Function of Applied Microwave Energy and Seed Depth

\begin{tabular}{|c|c|c|c|c|c|}
\hline \multirow{2}{*}{$\begin{array}{c}\text { Burial } \\
\text { Depth (cm) }\end{array}$} & $\mathbf{5}$ & $\mathbf{5}$ & $\mathbf{3}$ Microwave Energy $\left(\mathrm{J} \mathrm{cm}^{-2}\right)$ \\
\hline \hline 0.5 & $35.0^{\mathrm{ab}}$ & $30.0^{\mathrm{b}}$ & $0.0^{\mathrm{c}}$ & $\mathbf{6 9 3}$ & 1040 \\
\hline \hline 5 & $27.5^{\mathrm{b}}$ & $30.0^{\mathrm{b}}$ & $12.5^{\mathrm{c}}$ & $0.0^{\mathrm{c}}$ & $0.0^{\mathrm{c}}$ \\
\hline 9.5 & $25.0^{\mathrm{b}}$ & $27.5^{\mathrm{bc}}$ & $47.5^{\mathrm{a}}$ & $0.0^{c}$ & $0.0^{c}$ \\
\hline \multicolumn{2}{|c|}{$\operatorname{LSD}(\mathrm{P}=0.05)$} & $0.0^{\mathrm{c}}$ & $0.0^{\mathrm{c}}$ \\
\hline
\end{tabular}

Note: Entries with different superscripts are significantly different from one another.

The $r^{2}$ value for this function is 0.70 . The results from the second repetition of this experiment were also the same as the first.

\subsection{Experiment 4 - Wild Radish Seeds in Soil}

Wild radish seed germination was low and variable in the control treatment; however there was some germination in every replicate of the control. Seed germination decreased with increasing microwave energy, but increased with increasing burial depth (Table 3).

Many seeds from the higher microwave treatments appeared to have expressed oil during their treatment as there were distinctive oil stains on the filter paper envelopes in which the seeds were placed (Figure 9). The dose response (Figure 10) is described by:

$$
S=0.16 \cdot \operatorname{erfc}\left[0.04\left(E \cdot e^{-0.12 D}-189\right)\right]
$$

The $r^{2}$ value for this function is 0.73

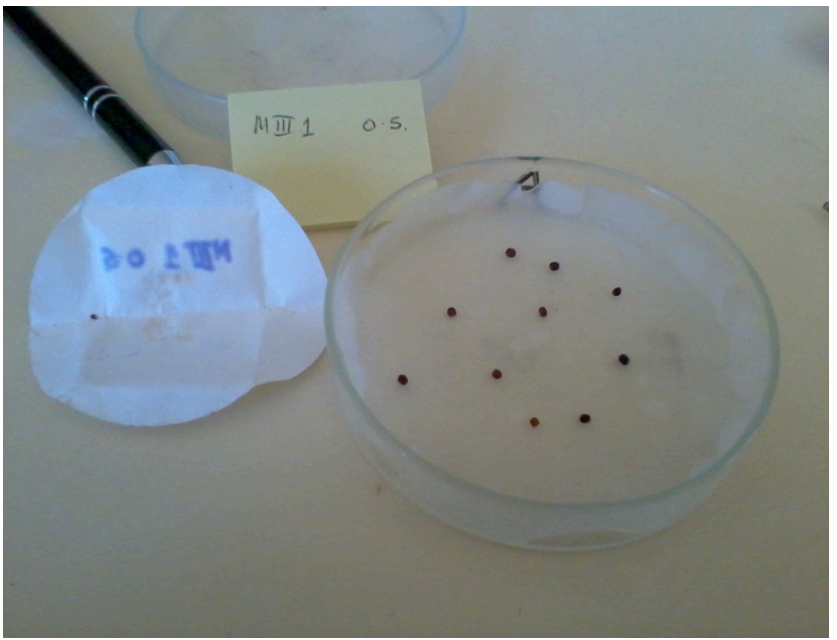

Figure 10: Preparation of wild radish seeds for germination test after microwave treatment (Note: oil stain on filter paper to the left, which was used to hold seeds during microwave treatment).

\subsection{Experiment 5 - Wild Radish Plants in Soil}

Wild radish plants showed only a single response to microwave treatment (Figure 11); unlike the ryegrass plants. The Normalised dose response is described by:

$$
S=0.51 \cdot \operatorname{erfc}[0.06 \cdot E-31.6]
$$

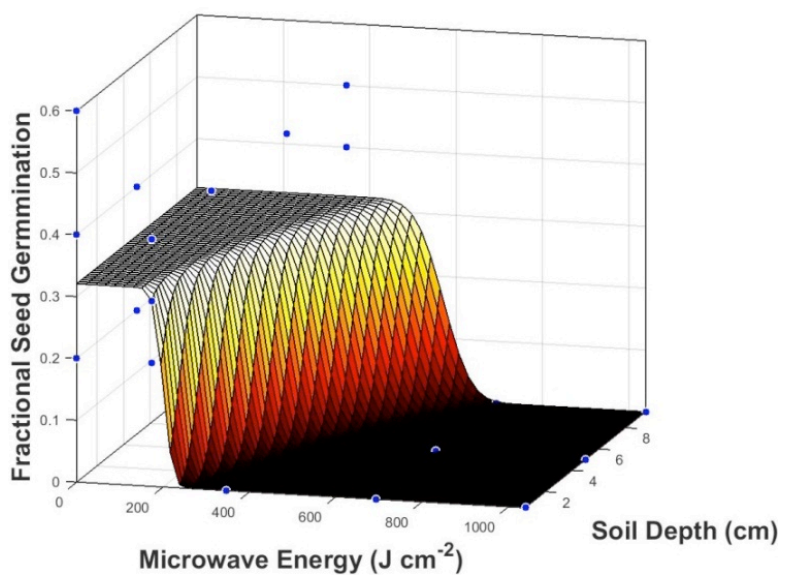

Figure 11: Response of wild radish seeds as a function of applied microwave energy and soil depth.

The $r^{2}$ value for this function is 0.99 . Therefore the equivalent of an $L D_{50}$ microwave energy dose for wild radish plants is $31.6 \mathrm{~J} \mathrm{~cm}^{-2}$.

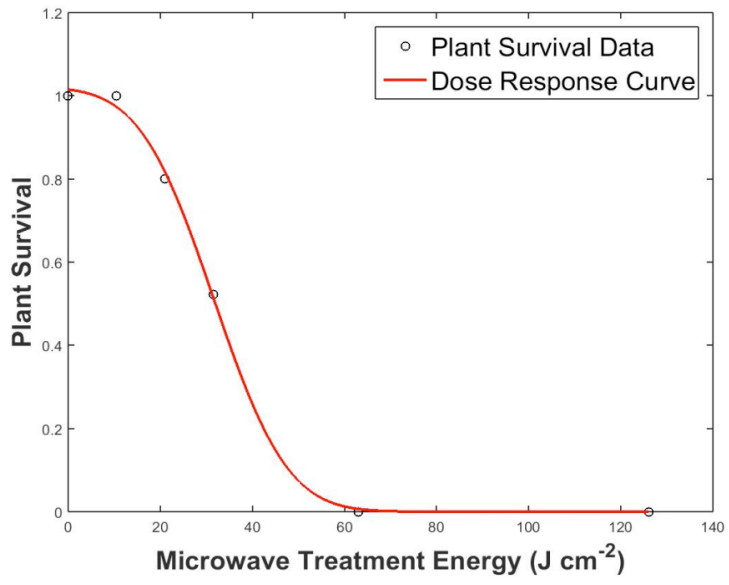

Figure 12: Response of wild radish plants as a function of applied microwave energy. 


\section{DISCUSSION}

This study demonstrates that microwave energy kills ryegrass and wild radish plants and seeds in soil. Ryegrass plants show a double response to microwave treatment, with some efficacy due to low application energy; however $100 \%$ mortality required $370 \mathrm{~J} \mathrm{~cm}^{-2}$ of microwave energy. This is probably because grasses have their apical meristem at the base of the plant in or near the soil surface, where it is slightly protected from microwave heating by the leaves above and the surrounding soil. This is important to consider when designing an effective microwave applicator system for microwave weed management in cropping systems.

Complete wild radish plant mortality was achieved when $60 \mathrm{~J} \mathrm{~cm}^{-2}$ of microwave energy was applied. This difference in energy requirements between ryegrass and wild radish may be due to a combination of differences in plant geometry and the location of the apical meristems. Microwave heating is linked to the geometry of the heated object [14]. Wild radish, as a broad leafed plant, has larger leaf and stem structures than ryegrass and therefore heats faster than the thinner leafs and stems of ryegrass. The apical meristems of broad leafed plants are at the tips of the stems rather than at the base of the stem as in grasses; therefore rapid microwave heating in the structures of broad leafed plants may rupture plant stem cells [20] cutting off supporting plant functions from the apical meristems, thus preventing growth. In the case of grasses, destruction of plant stems may not affect the apical meristems and therefore the plant can regrow.

Complete ryegrass seeds mortality in the top $2 \mathrm{~cm}$ of dry sand was not achieved even after applying 3,530 $\mathrm{J} \mathrm{cm}^{-2}$ of microwave energy because the dry sand has very low dielectric properties and does not absorb microwave energy very well, while complete mortality of ryegrass seeds at the surface of wet sand was 1,176 $\mathrm{J} \mathrm{cm}^{-2}$ because moisture in the soil has a high dielectric constant that absorbs microwave energy well. Complete mortality of wild radish seeds in the top $5 \mathrm{~cm}$ of moist soil was achieved by applying $693 \mathrm{~J} \mathrm{~cm}^{-2}$ of microwave energy. This is lower than the ryegrass seeds in experiment 2 and may be related to the geometry and relative volume of wild radish seeds when compared to ryegrass seeds. Davis et al. [7] noted that both specific mass and specific volume of seeds influenced their susceptibility to microwave damage.
Weed control is achieved by intercepting a plant's life cycle when it is most vulnerable to the treatment method. This study demonstrates that although microwave treatment can kill weed seeds in the soil, emerged plants are much more vulnerable to microwave energy; therefore microwave weed control can be best achieved by applying microwave energy to emerged plants.

\section{CONCLUSION}

Microwave treatment kills annual ryegrass and wild radish plants and their seeds in the soil. Seed treatment requires higher energy applications than plant treatment and is conceptually similar to soil fumigation treatments. Soil treatment may have application in some high value horticultural crops, which already use soil fumigation. Microwave treatment of plants requires less energy, with wild radish requiring about $60 \mathrm{~J} \mathrm{~cm}^{-2}$ to achieve $100 \%$ mortality, while ryegrass plants require about $370 \mathrm{~J} \mathrm{~cm}^{-2}$ to achieve $100 \%$ mortality. Microwave treatment of growing plants can be compared to the application of herbicide. Therefore control of growing plants should be the focus of developing a commercially viable microwave weed control device for cropping systems.

\section{REFERENCES}

[1] McGillon T and Storrie A. Integrated weed management in Australian cropping systems - A training resource for farm advisors. CRC for Australian Weed Management: Adelaide, South Australia 2006.

[2] Stanton R, Pratley J and Hudson D. Annual ryegrass control affected by choice of management system. In: Proceedings Cairns, Queensland, Australia 2008; 306-308.

[3] Heap I. The international survey of herbicide resistant weeds www.weedscience.com. (accessed 21 October 2013.

[4] Brodie G. Derivation of a Cropping System Transfer Function for Weed Management: Part 1 - Herbicide Weed Management. Global Journal of Agricultural Innovation, Research \& Development 2014; 1 (1): 11-16. http://dx.doi.org/10.15377/2409-9813.2014.01.01.2

[5] Relyea RA. The Lethal Impact of Roundup on Aquatic and Terrestrial Amphibians. Ecological Applications 2005; 15(4): 1118-1124 http://dx.doi.org/10.1890/04-1291

[6] Wickerham EL, Lozoff B, Shao J, Kaciroti N, Xia Y and Meeker JD. Reduced birth weight in relation to pesticide mixtures detected in cord blood of full-term infants. Environment International 2012; 47(0): 80-85. http://dx.doi.org/10.1016/j.envint.2012.06.007

[7] Davis FS, Wayland JR and Merkle MG. Phytotoxicity of a UHF Electromagnetic Field. Nature 1973; 241(5387): 291 292.

http://dx.doi.org/10.1038/241291a0

[8] Davis FS. New techniques in weed control via microwaves. In: Proceedings to Southern Nurserymen's Association Conference. Nacogdoches Texas USA. 1974; 75-78. 
[9] Davis FS, Wayland JR and Merkle MG. Ultrahigh-Frequency Electromagnetic Fields for Weed Control: Phytotoxicity and Selectivity. Science 1971; 173(3996): 535-537. http://dx.doi.org/10.1126/science.173.3996.535

[10] Brodie G, Ryan C and Lancaster C. Microwave technologies as part of an integrated weed management strategy: a review. International Journal of Agronomy 2012. http://dx.doi.org/10.1155/2012/636905

[11] Vidmar M. An improved microwave weed killer. Microwave Journal 2005; 48(10): 116-126.

[12] Nelson SO. A review and assessment of microwave energy for soil treatment to control pests. Überblick und Beurteilung des Einsatzes von Mikrowellenenergie zur Schädlingsbekämpfung in Böden 1996; (1): 281.

[13] Sartorato I, Zanin G, Baldoin C and Zanche C. Observations on the potential of microwaves for weed control. Weed Research 2006; 46(1): 1-9. http://dx.doi.org/10.1111/j.1365-3180.2006.00484.x

[14] Brodie G. The influence of load geometry on temperature distribution during microwave heating. Transactions of the American Society of Agricultural and Biological Engineers 2008; 51(4): 1401-1413.
[15] Cronin NJ. Microwave and Optical Waveguides. J W Arrowsmith Ltd: Bristol 1995.

[16] Nikolova NK. Modern Antennas in Wireless Telecommunications. http://www.ece.mcmaster.ca/faculty/nikolova/antennas.htm. (accessed 5th of August, 2013).

[17] Velazquez-Marti B, Gracia-Lopez C and Plaza-Gonzalez PJ. Determination of dielectric properties of agricultural soil. Biosystems Engineering 2005; 91(1): 119-125. http://dx.doi.org/10.1016/j.biosystemseng.2005.02.004

[18] Von Hippel AR. Dielectric Materials and Applications. M.I.T. Press: Cambridge 1954

[19] Shen JB, Xu LY, Jin XQ, Chen JH and Lu HF. Effect of temperature regime on germination of seed of perennial ryegrass (Lolium perenne). Grass and Forage Science 2008; 63(2): 249-256. http://dx.doi.org/10.1111/j.1365-2494.2008.00630.x

[20] Brodie G, Jacob MV, Sheehan M, Yin L, Cushion M and Harris G. Microwave modification of sugar cane to enhance juice extraction during milling. Journal of Microwave Power and Electromagnetic Energy 2011; 45(4): 178-187.

Received on 25-03-2015

DOI: http://dx.doi.org/10.15377/2409-9813.2015.02.01.2

(C) 2015 Brodie and Hollins; Avanti Publishers.

This is an open access article licensed under the terms of the Creative Commons Attribution Non-Commercial License (http://creativecommons.org/licenses/by-nc/3.0/) which permits unrestricted, non-commercial use, distribution and reproduction in any medium, provided the work is properly cited. 


\section{University Library}

\section{- M M N E R VA A gateway to Melbourne's research publications}

Minerva Access is the Institutional Repository of The University of Melbourne

Author/s:

Graham Brodie,;Eloise Hollins,

Title:

The Effect of Microwave Treatment on Ryegrass and Wild Radish Plants and Seeds

Date:

2015-07-28

Citation:

Graham Brodie, \& Eloise Hollins, The Effect of Microwave Treatment on Ryegrass and

Wild Radish Plants and Seeds. Global Journal of Agricultural Innovation, Research \&amp; Development, 2 (1), pp.16-24. https://doi.org/10.15377/2409-9813.2015.02.01.2.

Persistent Link:

http://hdl.handle.net/11343/58282 